\title{
20 \\ Using IDEF0 to develop \\ Generic Business Process Models
}

\author{
R. Maull, A Weaver, A Smart, SChilde, \\ School of Computing, University of Plymouth, Plymouth, UK \\ Telephone 01752232545 \\ Fax 01752232540 \\ E-Mail rmaull@plym.ac.uk
}

\begin{abstract}
This paper has two main elements. Firstly, the research team based at the University of Plymouth have identified three 'sets' of processes: manage, operate and support and we have further sub-divided the operate processes into three: product development, order flow and after-sales service. Using a Soft Systems approach we have developed a root definition and a conceptual model for the order flow process. The paper will describe the conceptual model in detail, illustrated through the use of the IDEF0 modeling technique.

The second major element of the paper is an illustration of how we have used the process models in small companies. We will provide a case study with reflections on how the generic model may be applied to help small companies improve their business processes.
\end{abstract}

\section{BACKGROUND TO THE RESEARCH}

The basic idea of a hierarchy of processes is important when considering generic processes for an industry type and the core processes within a company. The hierarchy of processes provides the framework within which the analysis and redesign will take place.

In the majority of documented BPR methodologies, including those developed by Coopers \& Lybrand (Johansson et al 1993), IBM (Kane 1986), British Telecom (Harvey 1994), Xerox and Lucas (Parnaby 1993), one of the initial activities is to identify the core business processes. In identifying the core processes the participants in the BPR project are defining boundaries within their organization using a process perspective. Examples of core process definition by companies can 
be found in Davenport (1993) and the Business Intelligence report (Harvey 1994) on BPR and many case studies in journal articles (Shapiro et al 1992, Davenport and Short 1990). The number of core processes within a company is very much dependent on the level of abstraction at which the organization decides the core process definition will be meaningful.

\section{BUSINESS PROCESSES}

The Business Processes concept is closely linked with Enterprise Integration (EI). EI is associated with the development of reference architectures. Unfortunately, much of this reference architecture work is at the abstract level. They are very high level frameworks which enable users to take a complete enterprise wide perspective on the organization. Their great strength is that they develop activity (function), information and human/organizational views, all of which are capable of being integrated together. Their great weakness is that they are not equipped with models which users can quickly pick up and use. We would argue that what industry requires are tailorable models, building blocks on which they can quickly develop business process and integration models. It is these building block models that we have set out to develop. Real benefits are expected with the integration of examples such as ours within the all embracing reference architectures.

Given our interest in developing re-usable business process models and their subsequent integration within EI reference architectures, we set out to ensure some compatibility of our UK government sponsored research with the international developments in reference architectures.

This research project has used the CIM-OSA (AMICE ESPRIT, 1989) framework to identify three types of processes within an organization. CIM-OSA was used because it is the major European initiative in reference architectures. As Vernadat (1996) reports, has been developed from a number of European wide ESPRIT projects over the last ten years and has a wide range of academic and industrial project partners. In addition other Enterprise Integration architectures e.g. CEN ENV (1990) and ARIS (Scheer 1992) are based on CIM-OSA. Internationally, GERAM (Williams 1995) uses CIM-OSA as one of its core elements along with PERA (Williams 1994). CIM-OSA identifies three types of processes Operate processes that add value. Support processes that enable the value adding processes to function e.g. personnel and finance processes. Manage processes, which are the processes that develop a set of business objectives, a business strategy and manage the overall behavior of the organization. 
We set out to identify a set of business process models for the operate processes.

\subsection{The "Operate" processes}

The "Operate" processes are those processes which directly produce value for customers, the core operational processes identified by Champy (1995) and Meyer (1993) for a business are "product development", "customer service" and "order fulfillment". The "product development" process transforms the actual or perceived requirements of a customer into a design that can be manufactured. The "customer service" process transforms knowledge of customer requirements and the market into customer orders. The "order fulfilment" process takes the order, manufactures and delivers the product to the customer.

The product development process adds value for the end customer by using knowledge to design a product to the customer's requirements. The customer service process adds value by translating customer requirements of a product into the value to be added by the other two operate processes. The order fulfillment process adds value by manufacturing and delivering a product to a customer.

The authors recognize that although the "operate" processes can be identified as individual processes it is the interaction of all three that results in the overall value added and hence the fulfillment of customer needs. However, it is not the purpose of this paper to describe these interactions. These are described more fully in a paper currently under preparation and available in draft form from the authors, see Smart et al (1997). This paper will focus on describing in detail one of the processes - the order fulfillment process. The generic model of the "order fulfillment" process has been developed using IDEF0 (CAM-I 1980).

\subsection{The development and validation of the generic "order fulfillment" process model}

Smart (1995 in a wide ranging survey of Process Analysis Tools identified three key issues that a process analysis method must support

1. The development of consensus regarding Weltanschauungs and objectives. Techniques must provide an easy to use/common language for communication and debate. The success of the technique depends upon the simplicity of the syntax and semantics employed by the technique. Consensus needs to be established regarding system boundary and purpose In addition, a coherent set of modeling rules are required to facilitate the modeling process itself: 
2. The description of a process in terms of systems parameters. That is inputs, transformation, outputs, receivers and feedback.

3. The identification of a systems hierarchy. The idea of hierarchy is based on a systems concept in which systems are composed of sub-systems (and processes of sub-processes). Harrington (1992) has proposed a hierarchy of macroprocesses, sub-processes, activities and tasks each of which represents further hierarchical detailing of the process. Techniques must facilitate the identification of sub-processes, activities and tasks within the whole process. This is so that each element of the system is seen in its proper context. Abilities to represent hierarchical decomposition and ensure that the context for a part of a model under detailed analysis is always known is advantageous when using a generic model. A company can focus on a part of the generic model it is particularly interested in and develop a further levels of detail without losing an understanding of the whole process.

Given these requirements we concluded that IDEF0 was the most appropriate modeling method to support activity based business process analysis. We recognize that IDEF0 is unsuitable for both dynamic modeling and information modeling. However, for identifying and providing a basis for improving the activities in a business process model (i.e., the three requirements set out above) we contend that IDEF0 is the most suitable method. For a further discussion on this issue, see the PAT report.

\section{Generic activities}

The information used to develop the generic process model has been extracted and assimilated from a number of sources. The activities that are carried out within the "order fulfillment" process were adapted from a generic task model developed by Childe (1991). Childe's task model was based on the proposition that there are a key set of tasks or activities which are consistent throughout manufacturing companies (all manufacturing companies order materials, take orders from customers etc.).

\section{Generic flows}

The types of flows that are modeled in the generic process model can initially be divided into physical and information flows i.e. flows of physical materials which are transformed by value adding activities and information flows where the value is in the information and not the medium of transmission e.g. a paper proforma or an electronic signal. The information flows can be further divided into seven categories of information described by Jorysz and Vernadat (1990). These seven categories of information are 
1) Product information describes what to produce e.g. Drawings, part lists

2) Process Information describes how the product should be produced e.g. process plans

3) Production Information describes the quantities to be produced and shop floor progress

4) Planning Information describes the schedules, inventories and plans

5) Resource Information describes the facilities that produce the products

6) Administrative information describes management information e.g. customer orders

7) Organization information describes responsibilities

The generic process model includes generic flows between activities representing the first six types of information. The seventh type of information about the organization and responsibilities is company specific. Although IDEF0 provides the facility to identify responsibilities by the addition of mechanism arrows on the bottom of activity boxes, the generic process model does not have any because of their company specific nature.

Generic flows were identified from IDEF0 models of manufacturing companies that had been produced by the authors in the course of their research work. Information was also distilled from other models produced in a number of different modeling techniques presented in literature.

\subsection{The generic "order fulfillment" model}

The generic "order fulfillment" model that has been developed currently includes over 110 activities integrated by the flows of physical and information entities. It is a model which has been validated with all industry types - although we recognize that the importance of certain activities in the model will differ depending on various organizational characteristics. A description and illustration of these characteristics is provided in Weaver (1995). The model below is a representation of the second highest level of abstraction of the "order fulfillment" process. The model extends to 5 lower levels of activities and flows. The complete model also includes a glossary of terms. 


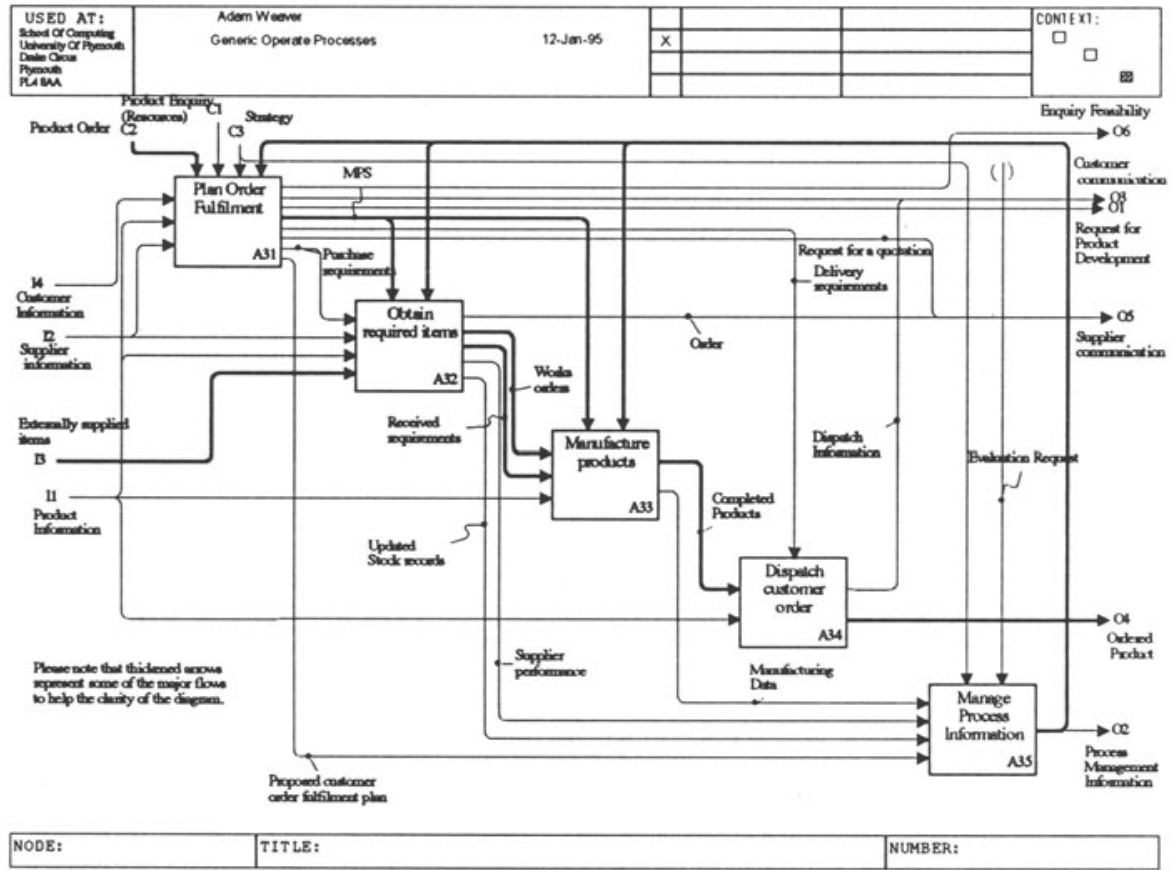

The event that triggers the commencement of activities within the order fulfillment process is arrival of an order for a product or an enquiry requesting feedback on the feasibility of fulfilling a possible order to a customer's requirements both events come from the "Get Order" process. The event that represents a full cycle of the process results in either an enquiry feasibility report sent to the "Get Order" process or an order delivered to a customer.

\section{CASE STUDY}

The objective of this phase of the validation approach was to find out if the model could be used by a company as a useful framework to help identify and understand their business processes. The idea of the model and its use as a framework was introduced to a local manufacturing company that was at the point of initiating a project to improve the management of what could be described as its order fulfillment process. The IT manager agreed to use the model as a starting point to develop a model of the company's existing order fulfillment process.

Background of the company

The company manufactures printed circuit boards (PCBs) under contract for a variety of customers. The quantity and complexity of individual PCBs per order 
varies considerably. The company has expanded rapidly over the past 5 years and was seeking to improve the management of orders throughout the business.

Use of the model as a framework

The IT manager was the main point of contact within the company. He acted as facilitator to a team using the model. The model and its use as a framework were introduced to the IT manager during a single meeting that lasted approximately 2 hours. A set of guidelines for the use of the model was not available at that time so a brief outline of the context, viewpoint, structure of the model and proposed approach to its use was given verbally.

The model was used by the IT manager as a template. Key personnel were interviewed and during the interview the IT manager described the activities that the model represented and their context in the overall process. The IT manager focused on those activities which were similar in nature and content to those actual activities undertaken by the individual. This part of the interview could be described as a "walk through" of the process.

\section{FEEDBACK ON THE USE OF THE MODEL IN THE COMPANY}

Issues that were raised during the meetings while "walking through" the model and altering it to represent the existing "order fulfillment" process included:

Allocation of responsibility - When adding mechanisms to indicate who carried out activities, it was necessary to clarify who was responsible for doing them. This initiated discussions about who was and should be responsible for activities and supplying information.

"Taken for granted - "Walking through" the model, interviewees were provoked into thinking about some of the activities that they did but had never really considered properly before. For example, "Produce simulation for decision making" [A3132] was initially dismissed, however on reflection the interviewees realized that they did simulate "what if" scenarios although the activity was not formally documented. This realization provoked ideas on how some of the knowledge could be captured in the future.

Ideas for Improvements - Discussing the activities represented by the model resulted in the identification of activities that the company did not currently carry out but should be done. For example, no one in the company had the responsibility for performing the activity "confirm order to customer" under circumstances where there were no queries relating to order. The procedure for confirming to a customer that the company was accepting the customer's order was later reviewed. 


\section{DISCUSSION}

As a result of this and other case studies applying the model the research team have identified a number of advantages of using a generic model.

1. It reduces the chance of the team reverting to a traditional functional view. As a result of the prevailing functional organizational mindset, process modeling teams can resort back to modeling departments e.g. Design or Manufacturing and to shy away from modeling the integrating elements. The scope of the model ensures that they focus on the whole process.

2. Reduces amount of modeling activity required. Process modeling can be a very time consuming task. Before we developed the generic model, the team have been involved in "fulfill order" process modeling, that has taken 12 - 18 man months of activity. Working from the generic model we estimate that this is reduced by $75 \%$.

3. Provides greater momentum than starting from a "blank sheet of paper". Starting from scratch is a daunting experience. In some cases it has been a major task to move modeling teams from project management to process modeling. The advantage of the generic model is that teams begin with a model and only have to work onwards to modify activities and linkages.

4. The standard models are not influenced by any political issues in the company. Models that are developed "in-house" can be influenced by senior management, who either want to throw a complimentary perspective on their own activities or develop models that appear to point the blame at other departments. The generics are free from this bias.

5. Team should feel able to criticize the standard models. Modellers can quickly feel proprietorial about their models. They may resist all attempts to change them. The generics are used on the basis of "no pride of ownership" and company members are encouraged to criticize and modify the models.

6. The activity of comparison encourages communication and understanding through debate. By comparing what we do with the model, it encourages companies to think through why they carry out activities in that way. Often, in our experience, a discussion ensues which exposes many of the underlying reasons behind why processes work in specific ways. It can be that the reasons that caused a process to be changed have changed themselves and particular aspects of the process no longer need to be carried out in that way.

\section{CONCLUSION}

The objective of this paper was to describe the development of a framework that would help manufacturing organizations identify and understand their business processes.

A high level business process architecture has been developed from a study of various business process architectures defined by specific manufacturing 
organizations and general models suggested in the BPR literature. The high level business process architecture groups the business processes within an organization under three headings. A set of standard business processes has been identified and defined under the "Operate" heading.

To define the four processes in more detail a model of processes has been developed. The purpose of the model was to represent the activities and flows that when integrated form the four "Operate" processes in a typical manufacturing organization. The model is not meant to be prescriptive and is not intended to show how a business should operate.

The model has been validated by a number of practitioners. They found that it represented a view of standard "Operate" processes within a typical manufacturing company. It was then used in a manufacturing company as a framework to help the company identify and understand its business processes. A case study of the company and its findings from using the model has been provided. The framework proved useful to the company in developing a model of their existing order fulfillment process.

The framework consisting of the high level business process architecture and model are currently at a stage of completeness where they can be used within manufacturing organizations. They will benefit from further development to incorporate new information and views gained from subsequent applications.

\section{ACKNOWLEDGEMENTS}

The research described in this paper has been funded by the DIP directorate of the UK's Engineering and Physical Science Research Council.

\section{REFERENCES}

AMICE ESPRIT, 1989, CIM-OSA Reference Architecture CAM-I (1980), Architectecture Manual ICAM Definition Method "IDEF-0", Arlington, Texas

CEN (1990) ENV 40 003, Computer-Integrated manufacturing -Systems Architecture - Framework for Enterprise Modeling. CEN/CENELEC, Brussels.

Champy J (1995), Re-engineering Management, HarperBusiness, NY Checkland P (1981), Systems thinking, systems practice, J Wiley \& Sons Childe S J (1991), The design and implementation of manufacturing infrastructure, PhD Thesis, Polytechnic South West, UK

Davenport T H and Short J E (1990), The new industrial engineering: information technology and Business Process Redesign, Sloan Management Review, Summer 
Davenport H J (1993), Process Innovation, Harvard Business School Press

Hammer M, Re-engineering Work: Don't automate, Obliterate, Harvard Business Review, July-August, 1990

Harrington H J, (1992), Business Process Improvement, McGraw-Hill

Harvey D (1994), Re-engineering: The Critical Success Factors. , Business Intelligence

Johansson H J, McHugh P, Pendlebury A J, Wheeler W A (1993), Business Process Re-engineering- BreakPoint Strategies for market dominance, J Wiley \& Sons

Jorysz H R, Vernadat F B (1990), CIM-OSA Part2: Information View, International Journal of Computer Integrated Manufacturing, vol. 3 No. 3

Kane E J (1986), IBM's Quality Focus on the Business Process, Quality Progress, April

Meyer C (1993), Fast Cycle Time, The Free Press, NY

Porter M E (1985), Competitive Advantage: Creating and Sustaining Superior Performance, The Free Press, NY

Parnaby J (1993), Business Process Systems Engineering, Lucas Industries plc, November

Scheer W A (1992) Architecture for Integrated Information Systems, SpringerVerlag, Berlin

Shapiro B P, Rangan V K, Sviokla J J (1992), Staple yourself to an order, Harvard Business Review, July-August

Smart PA, Maull R S, Childe S J, Bennett J, Weaver A M, (1995), Report on Process Analysis Tools, (Working Paper WP/GR/J/95010-3), EPSRC Grant No GR/J/95010, University of Plymouth, UK

Smart A Weaver A Maull R and Childe S (1997) A reference Model of Operate Processes for Process Based Change. Paper in preparation.

Weaver A M, (1995), A model based approach to the design and implementation of computer aided production management systems, $\mathrm{PhD}$ Thesis, University of Plymouth, UK

Vernadat F B, (1996) Enterprise Modeling and Integration. Chapman Hall Williams T J (1994) The Purdue Enterprise Reference Architecture. Computers in Industry 24 (2-3).

Williams T J (1995) Development of GERAM, a Generic Enterprise Reference Architecture and enterprise Integration Methodology. In Integrated Manufacturing Systems Engineering, Chapman and Hall, London 